\title{
ENGREF-FCAP “Flying Wood” Method to Characterize Unknown Central Africa Tropical Woods Relative of Their Drying
}

\author{
Merlin Simo-Tagne ${ }^{a}$, Romain Rémond ${ }^{b}$ \\ ${ }^{a}$ Douala Higher Institute of Technology (DIT), Douala, PO Box 1623, Cameroon \\ ${ }^{b}$ University of Lorraine, LERMAB, ENSTIB, Epinal, PO Box 1041, F-88051 cedex 9, France
}

\begin{abstract}
When we want to opposite excessive exploitation of some species of wood in the tropics, it is important to characterize unknown woods with intention of their valorization. This is most urgent than in the majority of these countries, only some species are highly exploited and the species less valorized are destroyed during the researches of known species in the forests. ENGREF-FCAP "flying wood" method is an alternative to classify unknown woods according to their drying. This method permits us to evaluate deformations of wood sample during a dissymmetrical drying and to estimate also evolution of their drying kinetic. The radius of the curvature of samples and drying kinetic permit us to compare the attacks of the drying air conditions on the samples. When these attacks are capable to destroy the quality of wood, a review of these conditions permits to want favorable conditions until we obtained the drying table of unknown woods.
\end{abstract}

Keywords: ENGREF FCAP 'flying wood” method-Tropical woods- Drying-Characterization- LERMAB.

\section{Introduction}

Tropical forests have a diversity species of woods often wrong exploited. Only some species have most exploited when the others (the majority) are destroyed for the simple wood heating. For the case of Cameroon, more than 300 species of wood are observed where 3 species (sapelle, obeche and azobe) represent $70 \%$ of the total production. For example in 2001, on the $247769 \mathrm{~m}^{3}$ of total rough imber exporting of Cameroon, $125845 \mathrm{~m}^{3}$ of rough imber represent only obeche [1]. A reason of this most exploitation of these species is the fact that obeche species shows a same behavior than temperate species [2]. It is important to increase the studies on the woods unknown or not exploited in order to optimize forest management and to increase economic profits. As masonry clay bricks [3], wood can be utilized like insulating materials.

ENGREF FCAP "flying wood" method is a tool developed at the "Ecole Nationale de Génie Rural, des Eaux et des Forêts" (ENGREF) of Nancy (France) which permits a continuously measures of the wood drying kinetic. In this communication, we have presented this method in the objective to characterize unknown woods and to construct their drying table. Experiments are doing on the frake wood (Terminalia Superba).

\section{Experimental Material and Method}

This method uses a non-symmetrical and unidirectional drying, migration of water on the sample is only possible on the above face, the five others faces are isolated with aluminum leaf. The choice of the non-symmetrical is doing with the desire to reduce the crack during the tests. Figure 1 below gives a comparison between a non-symmetrical drying used in this method and classical drying calling conventional. We note that in the non-symmetrical method, behaviors of the sample are opposite according to each phase of the drying. In the second phase, the principal face is on the tension and at the end of drying this face is on the compression. At the end of drying (when water content of the sample is equal equilibrium water content in the conditions of the drying), the sample returned in the initial state. In fact, in the first period of drying, all parts of the wood are in the non-hygroscopic phase and without modification are observed on the sample. The first modifications become when water content of surface of the wood is inferior of the water at the fiber saturation point. The tension of the sample increases until wood is in the non hygroscopic domain. When the water content is superior of the water at the fiber saturation point, the tension decreases and the radius of the curvature decreases also until the value zero.

${ }^{*}$ Corresponding author. Tel.: (+237) 94852402

E-mail: simotagne2002@yahoo.fr

(C) 2014 International Association for Sharing Knowledge and Sustainability

DOI: $10.5383 /$ ijtee.08.02.001 


\section{Classical convective drying}
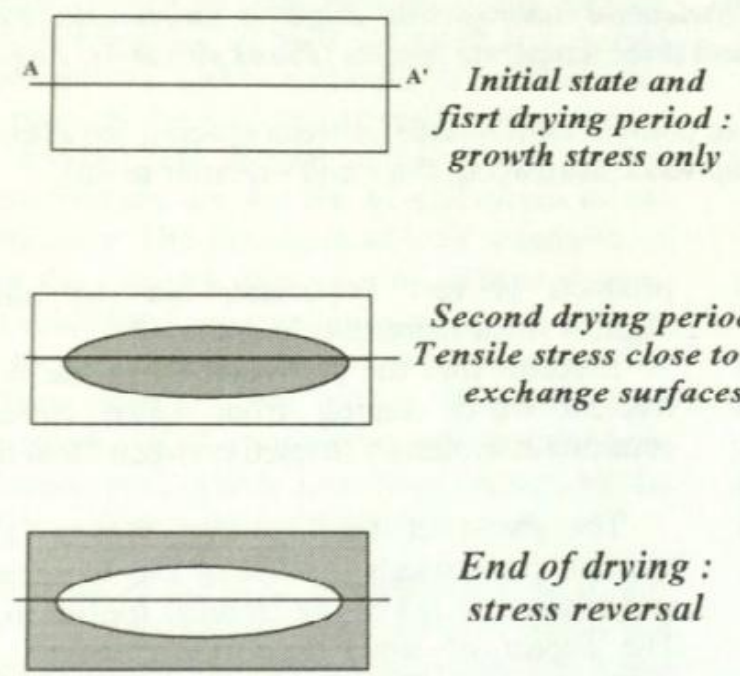

End of drying : stress reversal

\section{Non - symmetrical drying}

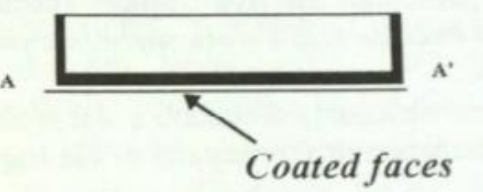
Tensile stress close to the

Compression
Second drying period : exchange surfaces

\section{Tension}

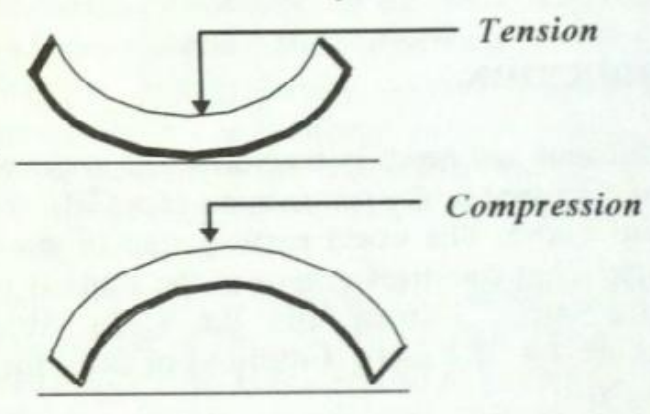

Then, the drying enters in the compressive domain until the end of drying. Evolution of the radius of the curvature in this domain is negative.

Table 1 below presents annual growth rings, anatomical direction and dimension of the two samples used during experiment.

Table 1: Used sampling collection

\begin{tabular}{|c|c|c|c|}
\hline $\begin{array}{c}\text { Species } \\
\text { and order } \\
\text { of test }\end{array}$ & $\begin{array}{c}\text { Dimension } \\
(\mathrm{cm})\end{array}$ & $\begin{array}{c}\text { Annual } \\
\text { growth rings }\end{array}$ & $\begin{array}{c}\text { Anatomical } \\
\text { direction }\end{array}$ \\
\hline $\begin{array}{c}\text { Frake, first } \\
\text { test } \\
\text { Scales 3 }\end{array}$ & $15 \times 10 \times 0.5$ & $\begin{array}{c}\text { "False" } \\
\text { quartersawn }\end{array}$ & Radial \\
\hline $\begin{array}{c}\text { Frake, 2 } \\
\text { test } \\
\text { Scales 3 }\end{array}$ & $12 \times 9.4 \times 0.5$ & $\begin{array}{c}\text { "False" } \\
\text { quartersawn }\end{array}$ & Radial \\
\hline $\begin{array}{c}\text { Frake, 2 } \\
\text { test } \\
\text { Scales 4 }\end{array}$ & $12 \times 9.4 \times 0.7$ & "False" & Radial \\
\hline
\end{tabular}

We have used sophistical apparatus of the laboratory of study and research on the wood material (LERMAB). We have showed experimental material in the figure 2. Different apparatus are: one oven to maintain temperature and relative humidity in the desire values, a cryothermostat to adjust the values of temperature, a computer to visualize evolutions of selected parameters during the experiment, HP central and megohmmeter to ameliorate conversion between tension and selected parameters. In the oven, we have put scales and apparatus to measure respectively mass and deformation of the sample during experiment, Figure 3.

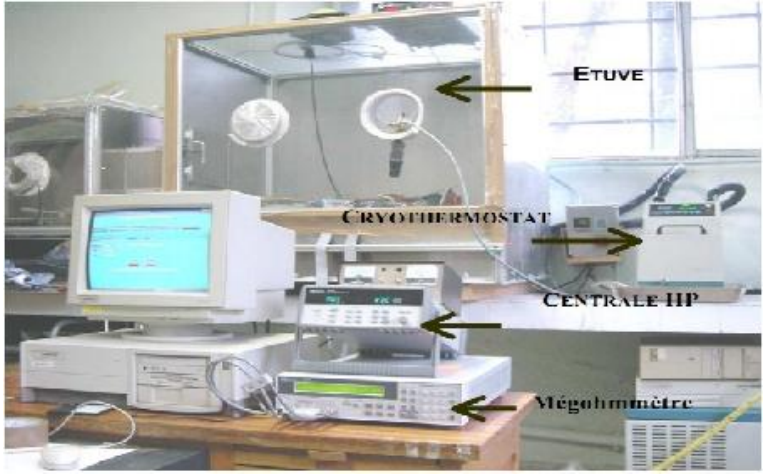

Fig.2: Experimental apparatus of acquisition of the measures and to fix relative humidity and temperature [2]

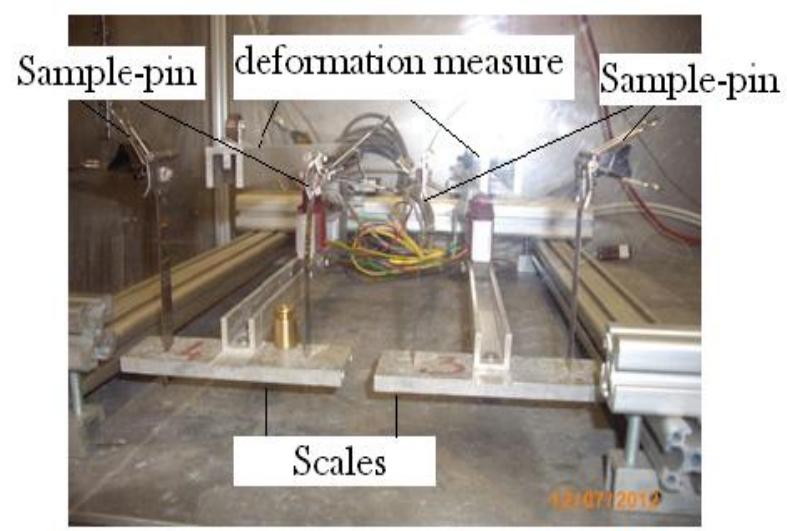

Fig.3: Scales and apparatus to measure the deformations of the sample. 
Figure 4 shows the setting of the sample (in the oven) during the first test.

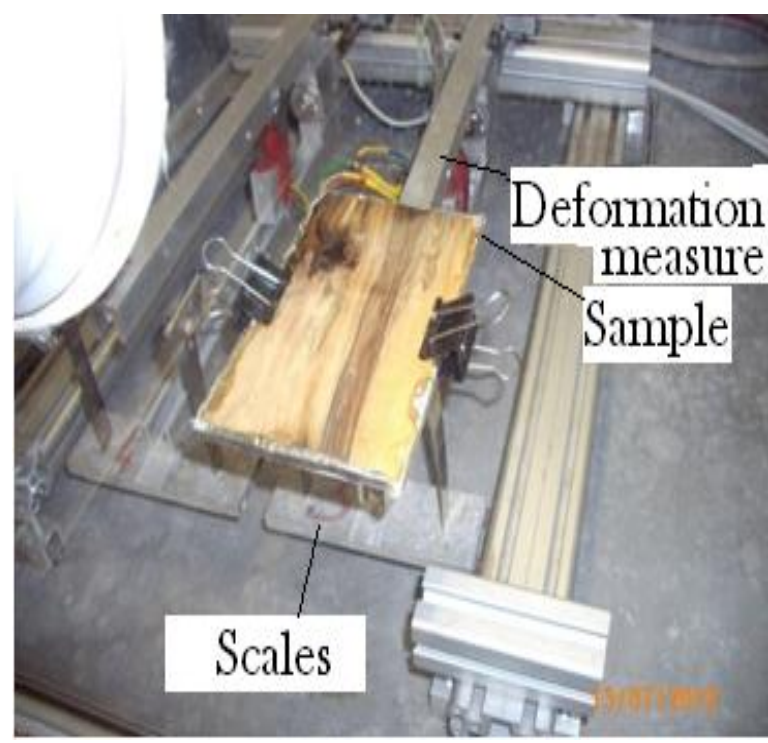

Fig.4: Fixed sample during the test

\section{Results and Discussion}

\subsection{Air conditions during the test}

Figures 5 and 6 below show values of different temperature (dry Ts, exterior $\mathrm{Tr}$ and humid $\mathrm{Th}$ ) used during respectively the test 1 and 2. In each test, relative humidity is equal to $59 \%$. In the first test, air drying conditions in the oven are constant. In the second, we have reduced humid temperature after 20 hours of drying. Thus, we used conditions of exterior air in the tropical region of central Africa, the same conditions used during a solar drying. In the second test, we study the influence of the variation of temperature on the radius of the curvature i.e. on the quality of the wood.

Table 2 below gives initial, final and anhydrous mass of the samples. We used these values to deduce water content of the sample during experiment. $\mathrm{M}$ is the mass of all the sample and $m$ is the mass of the one of two ( $j=1$ or 2$)$ part of the sample at the end of experiment used to obtain rapidly the anhydrous mass and to deduce water content. We have used three samples, one during the first test (scales number 3 is used) and two during the second test (scales number 3 and number 4 ). During second test, we have used two samples with different thickness $(5 \mathrm{~mm}$ and $7 \mathrm{~mm})$. Second test permits us to verify the first test and to study the effect of variation of temperature and thickness on the pile of wood.

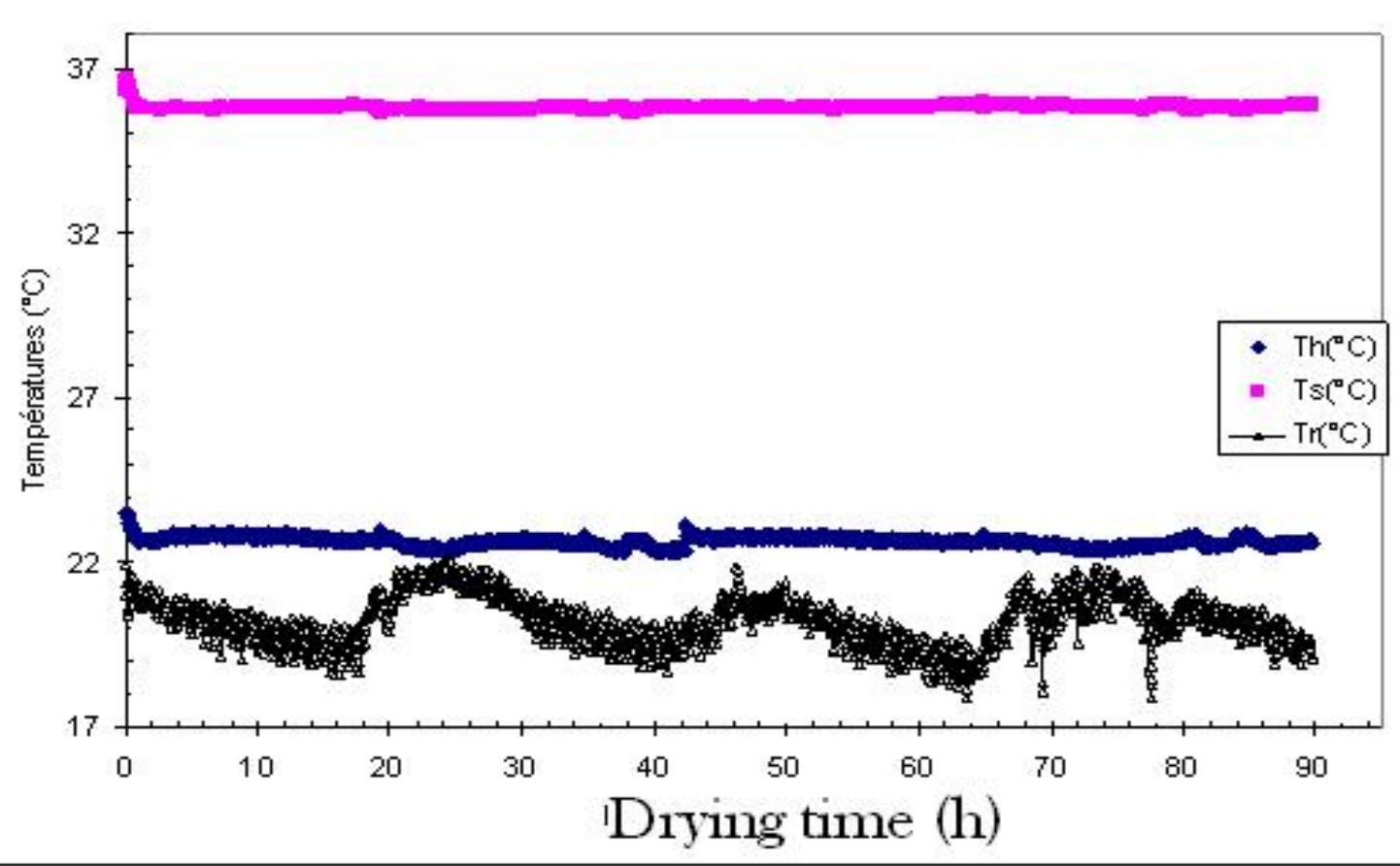

Fig.5: Temperatures evolution in function of drying time during first test $(\mathrm{HR}=59 \%)$. Th: humid temperature; Ts: dry temperature; Tr: exterior temperature. 


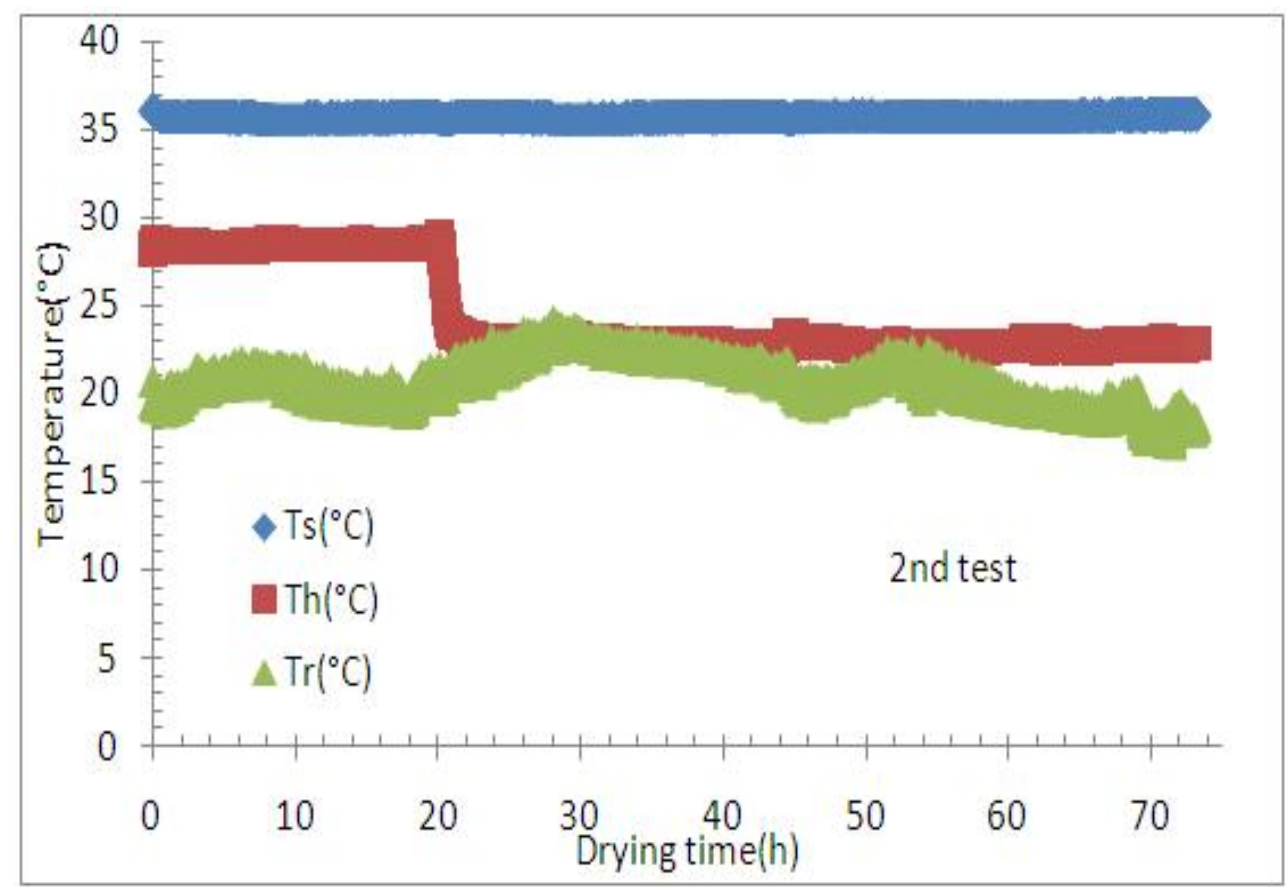

Fig.6: Temperatures evolution in function of drying time during second test. Th: humid temperature; Ts: dry temperature; Tr: exterior temperature.

Table 2: Initial (i), final (f) and anhydrous (o) mass of the samples

\begin{tabular}{|c|c|c|c|c|c|c|c|c|}
\hline Species and order of test & $\mathbf{M}_{\mathbf{i}}(\mathrm{g})$ & $\mathbf{M}_{\mathbf{f}}(\mathrm{g})$ & Number & $\mathbf{m}_{\mathrm{f}}(\mathrm{g})$ & $\mathbf{m}_{\mathrm{o}}(\mathrm{g})$ & $\mathbf{X}_{\mathrm{fj}}(\%)$ & $\mathbf{X}_{\mathrm{f}}(\%)$ & $\mathbf{M}_{0}(\mathrm{~g})$ \\
\hline \multirow{2}{*}{$\begin{array}{l}\text { Frake, first test } \\
\text { Scales } 3\end{array}$} & \multirow[b]{2}{*}{68} & \multirow[b]{2}{*}{33.3} & 1 & 4.188 & 3.854 & 8.667 & \multirow[t]{2}{*}{8.429} & \multirow[t]{2}{*}{30.859} \\
\hline & & & 2 & 4.108 & 3.797 & 8.429 & & \\
\hline \multirow{2}{*}{$\begin{array}{c}\text { Frake, second test } \\
\text { Scales } 3\end{array}$} & \multirow[b]{2}{*}{54.3} & \multirow[b]{2}{*}{29.4} & 1 & 3.123 & 2.858 & 9.272 & \multirow[t]{2}{*}{9.286} & \multirow[t]{2}{*}{26.902} \\
\hline & & & 2 & 3.326 & 3.043 & 9.30 & & \\
\hline \multirow{2}{*}{$\begin{array}{l}\text { Frake, second test } \\
\text { Scales } 4\end{array}$} & \multirow[b]{2}{*}{59.5} & \multirow[b]{2}{*}{36} & 1 & 5.494 & 4.978 & 10.366 & \multirow[t]{2}{*}{10.472} & \multirow[t]{2}{*}{32.590} \\
\hline & & & 2 & 5.676 & 5.133 & 10.579 & & \\
\hline
\end{tabular}

\subsection{Results}

We have take as parameter of deformation the radius of the curvature. This radius permits to obtain the maximum of curvature of each sample. Figure 7 shows temporal evolutions of the radius of curvature and the water content of ours samples with $5 \mathrm{~mm}$ of thickness during the two tests. We note that diminution of humid temperature cannot have a significative influence on the evolution of the water content. But, if this modification is important, it is possible to observe a great variation of the evolution of water content. At the time of the start of the drying of test 2, humid temperature is most important, consequently, we note that drying kinetic and radius increase when we reduced humid temperature. In the first test, humid temperature is constant and evolution of radius is most regular than the second test. During establishment of the drying table, is most important to control the state of the wood plank because it is possible to destroy the quality of the plank when we want to accelerate the drying. After 60hours of the drying, the radius of curvature becomes negatives. Figure 1 indicates that it is in this moment that the compression of the sample becomes until the end of the drying. We observe that, in the start of the drying (before 20hours of the drying), the radius of the two samples is not equal, nevertheless the conditions of air are the same. According to us, the difference of initial water content of the two samples is the reason. In effect, when wood have most humidity, these elastic properties increase and the radius becomes most important. Figure 7 shows that initially, the sample in the first test has $130 \%$ of humidity when the sample in the second test has $105 \%$ of humidity. We have with satisfaction that the two samples present same final water content. 


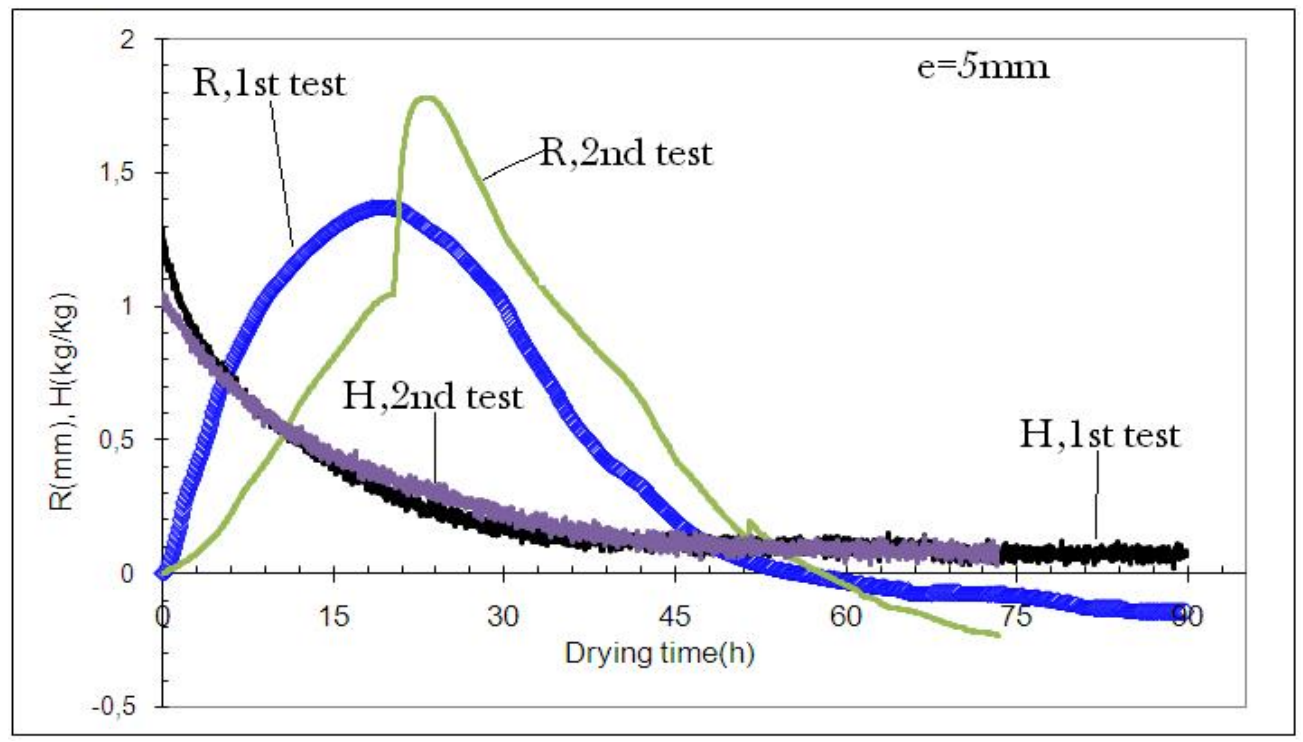

Fig.7: Radius of the curvature $(\mathrm{R})$ and humidity $(\mathrm{H})$ during the two tests for $\mathrm{e}=5 \mathrm{~mm}$.

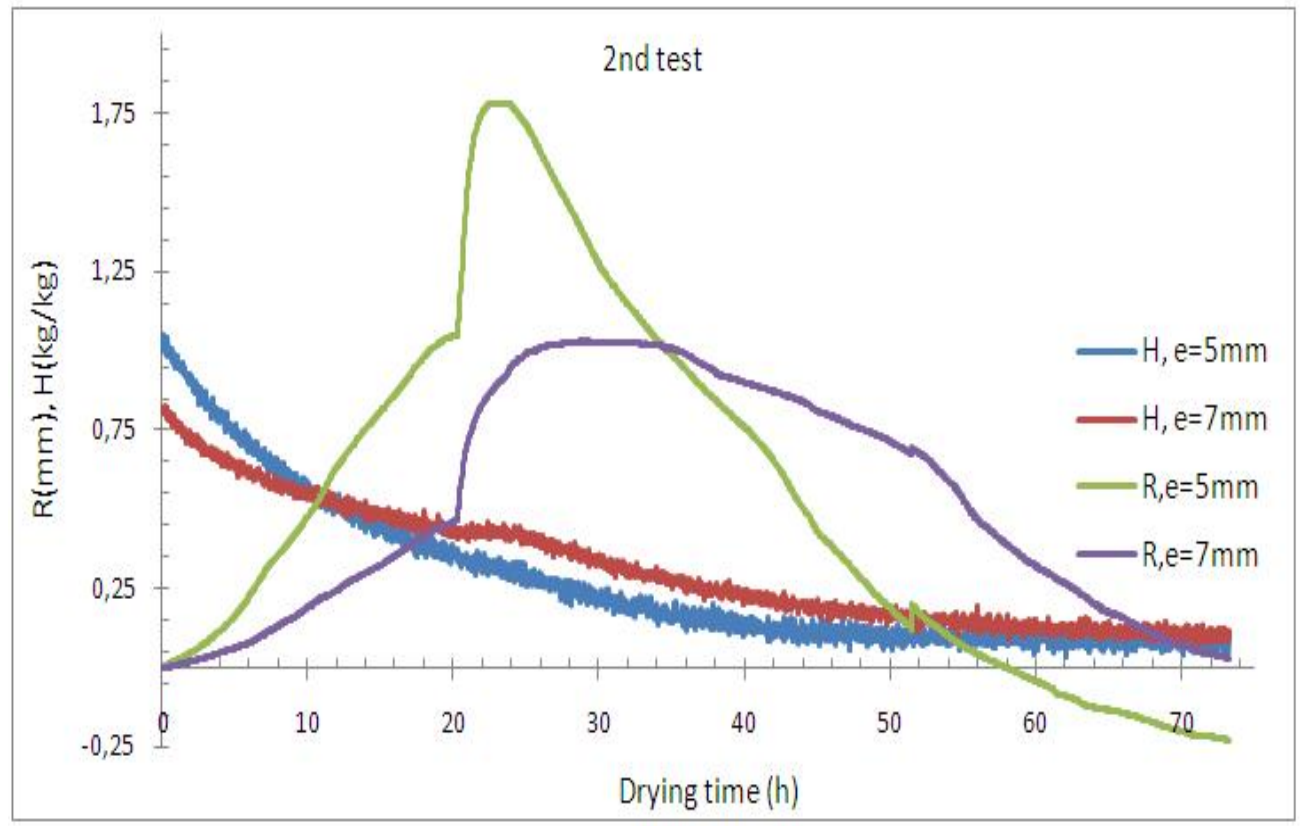

Fig.8: Radius of the curvature $(\mathrm{R})$ and humidity $(\mathrm{H})$ during second test for $\mathrm{e}=\mathbf{5 \mathrm { mm }}$ and $\mathrm{e}=\mathbf{7} \mathrm{mm}$

In the same condition, we have put two samples in the oven with the different thickness $(5 \mathrm{~mm}$ and $7 \mathrm{~mm})$. We have obtained figure 8 above. We note that condition of air most affect the sample that has a less thickness. Diminution of humid temperature gives a hard drying and deformation of the sample increases. Thus, the values of humid temperature have a most influence on the mechanics of the wood that on her drying kinetic. Figure 8 shows that when the thickness of the wood decreases, his torsion increases. Consequently, if we want to dry many planks together with different thickness of the same species, it is important to use the conditions relative of the plank who have a small thickness. On the figures 7 and 8 , we note that the phase where drying kinetic is constant is absent, because, the first phase of the drying is also absent [5]. In addition to the previous observation, we note that the torsion of the wood becomes in the non-hygroscopic domain. It is true that many researchers said that torsion becomes when the wood is in the hygroscopic domain, but [6] indicates that it is possible to observe the torsion of the wood in the nonhygroscopic domain.

\section{Conclusion}

In this paper, we have showed that ENGREF-FCAP 'flying wood" method presents many characteristics whose we can used to establish the drying table of many unknown tropical woods species. Also, we can use this to ameliorate drying table with integration of locality of origin of the tree which gives wood. Effectively, we have obtained in this study that Frake is easy to dry. In the conditions (dry temperature $=32^{\circ} \mathrm{C}$, Humid temperature between 20 and $30^{\circ} \mathrm{C}$ and Relative humidity neighbouring that $59 \%$ ), torsion of a plank of frake with 5 or $7 \mathrm{~mm}$ of thickness is less than $1.75 \mathrm{~mm}$. 


\section{Acknowledgments}

The principal author would like to thank Mr Tristan Stein for the sampling collection of our woods and the setting of apparatus measures. I wish that Professors Yann Rogaume and André Zoulalian receive my great thanks for all administrative procedure to facilitate my post doctorate stage and my integration in the University of Lorraine, Epinal France. This same author also congratulates the International Tropical Timber Organization (ITTO) who financed this work.

\section{References}

[1] La Lettre de l'ATIBT. Commerce mondial des bois tropicaux : entre demande asiatique et pression écologiste occidentale. $\mathrm{n}^{\circ} 16$, été 2002.

[2] A.C. Kouchade. Détermination en routine de la diffusivité massique dans le bois par méthode inverse à partir de la mesure électrique en régime transitoire. Thèse de Doctorat de l'ENGREF, 23 Septembre 2004.
[3] A. Alami. Mechanical and thermal properties of solid waste-based clay composites utilized as insulating materials. Int. J. of Thermal \& Environmental Engineering Vol 6 (2) (2013) 89-94 DOI: 10.5383/ijtee.06.02.007

[4] T.D.O. Brandao Alcir. Classification des bois tropicaux vis-à-vis du séchage : la méthode ENGREF-FCAP-Flying Wood. Thèse de Doctorat de l'ENGREF, 02 Octobre 1996.

[5] S. Zohoun. Détermination de la diffusivité massique dans le domaine hygroscopique du bois. Comparaison des mesures en régime permanent et transitoire.Thèse de Doctorat de l'Institut National Polytechnique de Lorraine, 02 Juin 1998.

[6] G.M. Pontin.Propriétés physico-mécaniques de trois bois au dessous et au-dessus de la saturation des membranes. Mémoire de maîtrise en science, Université de Laval, Avril 2005. 